\title{
The Analysis on the Evaluation of Shanghai Tap Water Quality in Terms of Inorganic Anion Concentration
}

\author{
Dongjing Yao ${ }^{1}$, Kaihang Zhang ${ }^{2 *}$, Chu Wang ${ }^{1}$, Ling Zhu ${ }^{1}$ \\ ${ }^{1}$ Department of Geography, Shanghai Normal University, Shanghai, 200234, China \\ ${ }^{2}$ Institute of Tourism, Shanghai Normal University, Shanghai, 200234, China
}

\begin{abstract}
By taking tap water samples from every district and county in Shanghai, we analyze six types of inorganic anions contained in these water samples, namely $\mathrm{Cl}^{-}, \mathrm{Br}^{-}, \mathrm{NO}_{3}{ }^{-}, \mathrm{NO}_{2}{ }^{-}$, $\mathrm{PO}_{4}{ }^{3-}$ and $\mathrm{SO}_{4}{ }^{2-}$, by applying the Ion Chromatography System. The results indicate that among these six inorganic anions in Shanghai tap water, $\mathrm{Cl}^{-}$has the highest concentration while $\mathrm{NO}_{2}^{-}$the lowest. Using the Nemerow Index in evaluating the inorganic anions in Shanghai tap water, we find that the average compliance rate of tap water in Shanghai is 58.3 percent, and that phosphorus pollution is serious. When $\mathrm{PO}_{4}{ }^{3-}$ is not calculated, tap water in Shanghai can be labeled as light pollution in general, from the suburbs to city areas tending to be cleaner; when $\mathrm{PO}_{4}{ }^{3-}$ is calculated, tap water in Shanghai is moderately polluted, and pollution in coastal areas is more serious than in inner areas.
\end{abstract}

Keywords-inorganic anions; the nemerow index; tap water quality evaluation.

\section{INTRODUCTION}

According to a study by the World Health Organization, $80 \%$ of human diseases have something to do with water. Research on Disinfection By-products (DBPs) began in the 1970s. American Scientists first discovered the existence of DBPs in 1974, and in 1976 it was proved that Chloroform, a disinfection by-product, could cause tumors in experimental animals ${ }^{[1,2]}$. People began to focus on the study of DBPs in drinking water from then on.

In the 1980s and 1990s, Epidemiologists found that the incidence of some cancers had potential relevance to DBPs ${ }^{[3]}$. Over 600 types of DBPs have been found so far. The amount of chlorine dosage affects the concentration of DBPs. For example, the heavier the chlorine dosage is, the easier it is to generate MX; whereas when there is excessive chlorine, the amount of MX drops ${ }^{[4]}$. Reaction time of chlorine also has an impact on the generation of DBPs. If chlorine dioxide is added before filtration, then the concentration of chlorate and chlorite increase rapidly, almost vertically; whereas their concentration stops rising or rises very slowly if chlorine dioxide is added after filtration $^{[5]}$. In order to eliminate the chlorination byproducts, ozone was firstly used as a disinfectant in Holland in the early 20th century. Although this way would not generate chlorination DBPs (eg THMs), it is likely to produce bromate when there is high concentration of $\mathrm{Br}$ - in the original water ${ }^{[6]}$.

As an international metropolis with a large population,
Shanghai demands more water supply and higher qualified water. Statistics show that the quality detection of tap water items increased from 16 to 89 since 1950 to 2000 years in Shanghai. The method of chlorine disinfection is widely used in Shanghai.

\section{STUDY AREA}

The total area of Shanghai is about $6340.5 \mathrm{Km}^{2}$, and its population is about 25 million. Composed of 16 districts and 1 county, Shanghai is the most developed area in China. There are 33127 rivers, and the total length is about 24915 $\mathrm{Km}$. The total length of water supply pipelines is about $27858.08 \mathrm{Km}$. Altogether 10 water supply companies are in charge of water supply in Shanghai, with total water supply being about 3.09 billion $\mathrm{m}^{3}$ every year, and daily water supply about 10.7 million $\mathrm{m}^{3}$.

63 water samples were collected in Shanghai (Fig.1) from November 2012 to February 2013, which were mainly collected from water pipes in households, office buildings or metro stations.

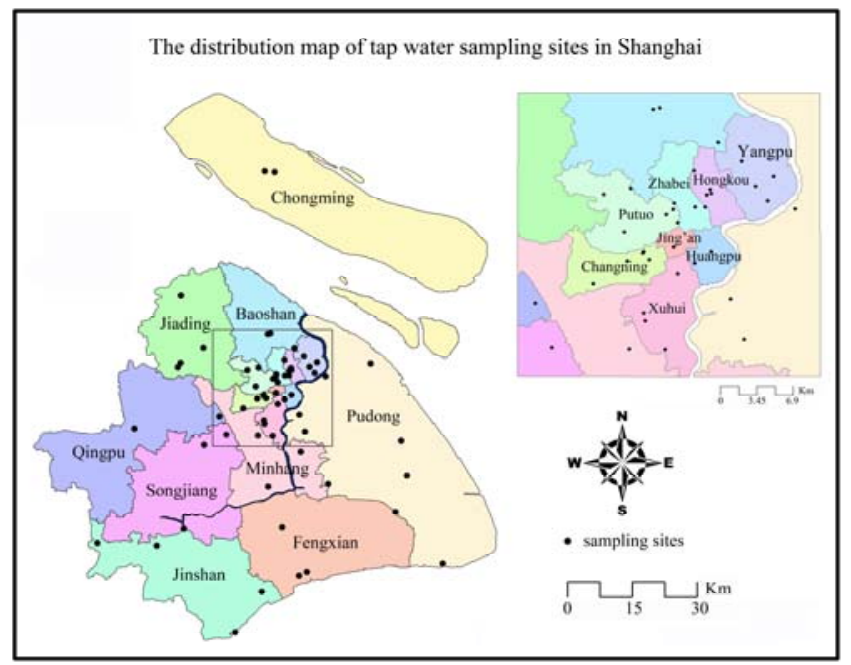

Figure 1. The distribution map of tap water sampling sites in Shanghai

Sampling devices are $250 \mathrm{ml}$ polyethylene sampling bottles. The bottles must be washed by the Sampling water at least 3 times before sampling, and the samplings were immediately incased in ice preservation box in order to take them to the laboratory. If there is no time to detective, we 
will put them into constant temperature $\left(4^{\circ} \mathrm{C}\right)$ refrigeration, to restrain biological activity and reduce the speed of physics volatilization and slow down chemical reaction ${ }^{[7]}$.

\section{DATA AND METHOD}

The ion chromatographic method is used by detecting inorganic anions, which has the characteristics of simple operation, fast analysis speed, high sensitivity and various anionic detection at the same time ${ }^{[8]}$, so it is widely used in water quality analysis, food analysis, and the application of environmental protection. Inorganic anions include $\mathrm{Cl}^{-}$、 $\mathrm{Br}^{-} 、 \mathrm{NO}^{3-}, \mathrm{NO}^{2-}, \mathrm{PO}_{4}{ }^{3-}$ and $\mathrm{SO}_{4}{ }^{2-}$. Each sample was detected at least three times, the range of error control between $95 \%$ and $105 \%$, and we get 63 series of data.

The Nemerow index ${ }^{[9]}$ is used to evaluate water quality, because it can consider maximum and average of single factor index effect on the composite index, the calculation formula is as follows,

$$
\mathrm{P}=\sqrt{\frac{\left(C_{i} / S_{i j}\right)_{\max ^{2}+\left(C_{i} / S_{i j}\right)_{a v e}{ }^{2}}^{2}}{2}}
$$

$P$ is the Nemerow index; $C_{i}$ is measured concentration of the ith pollution factor; $S_{i j}$ is the standard value of the ith pollution factor of the jth use. $P$ has a direct impact on the water quality evaluation, so we establish the relationship between the polluted situation of water quality and classification (table 1).

TABLE I. THE RELATIONSHIP BETWEen THE NEMEROW WATER QUALITY INDEX AND CLASSIFICATION

\begin{tabular}{|l|l|l|l|l|l|}
\hline P & $<1$ & $1 \sim 2$ & $2 \sim 3$ & $3 \sim 5$ & $>5$ \\
\hline classification & clean & $\begin{array}{l}\text { mild } \\
\text { contamination }\end{array}$ & $\begin{array}{l}\text { middle } \\
\text { level } \\
\text { pollution }\end{array}$ & $\begin{array}{l}\text { heavy } \\
\text { pollution }\end{array}$ & $\begin{array}{l}\text { severe } \\
\text { contamination }\end{array}$ \\
\hline
\end{tabular}

\section{RESULTS AND DISCUSSION}

\section{A. Inorganic anions concentration in the tap water samples}

By testing the water samples, we acquire such a table as shows the average concentration of inorganic anions in tap water of different areas in Shanghai.

The average concentration of $\mathrm{Cl}^{-}$in tap water of the whole city of Shanghai is $54.80 \mathrm{mg} \cdot \mathrm{L}^{-1}$. Except Chongming County, its $\mathrm{Cl}^{-}$average concentration as high as 101.65 $\mathrm{mg} \cdot \mathrm{L}^{-1}$ which slightly overpasses the respective standard for drinking water quality of China, the average concentration of $\mathrm{Cl}^{-}$in tap water of all the other districts of Shanghai are within the standard for drinking water quality of China. Since $\mathrm{Cl}^{-}$comes mainly from natural water, the areas which are nearer to the sea, lakes or rivers have tap water with higher $\mathrm{Cl}^{-}$concentration, and the central districts have tap water with lower $\mathrm{Cl}^{-}$concentration. Furthermore, city areas have better disinfection techniques than the suburban county, so they can keep $\mathrm{Cl}^{-}$concentration lower in processed drinking water.

The average concentration of $\mathrm{NO}_{2}^{-}$in tap water of the whole city of Shanghai is $0.45 \mathrm{mg} \cdot \mathrm{L}^{-1}$, which is within the standard of drinking water quality of China. $\mathrm{NO}_{2}^{-}$was not detected in the water samples from six districts of the city. On one hand, $\mathrm{NO}_{2}{ }^{-}$is unstable; on the other hand, the result of it is likely to be affected or covered by that of $\mathrm{Cl}^{-}$which is close in peak time and of higher concentration. Two sampling sites, one in Songjiang District, another in Yangpu District, were found to have concentration of $\mathrm{NO}_{2}^{-}$above $6 \mathrm{mg} \cdot \mathrm{L}^{-1}$. However, other sampling sites in these two districts were not. Not considering the water sources or the process of water plants, that might be caused by secondary pollution within pipeline transportation. The concentration of $\mathrm{NO}_{2}{ }^{-}$in the sampling site of Luchaogang Town surpasses $2 \mathrm{mg} \cdot \mathrm{L}^{-1}$, which is also above China's standard for drinking water. With the surface water rather severely polluted in this area, the concentration of $\mathrm{NO}_{2}^{-}$in tap water is indirectly raised.

The average concentration of $\mathrm{Br}^{-}$in tap water of the whole city of Shanghai is $1.34 \mathrm{mg} \cdot \mathrm{L}^{-1}$, which is above the standard limit of drinking water quality of China. Research shows that $\mathrm{Br}^{-}$in tap water is $0.0147 \sim 0.2 \mathrm{mg} \cdot \mathrm{L}^{-1}$, and that in sea water it is much higher, being $41 \sim 71 \mathrm{mg} \bullet \mathrm{L}^{-1}$. Therefore, the invasion of sea water constitutes the main cause for $\mathrm{Br}^{-}$ in fresh water ${ }^{[10]}$.

The average concentration of $\mathrm{NO}_{3}{ }^{-}$in tap water of the whole city of Shanghai is $9.82 \mathrm{mg} \cdot \mathrm{L}^{-1}$, which is close to $10 \mathrm{mg} \cdot \mathrm{L}^{-1}$, the standard limit of drinking water quality of China. It is found from the average concentration results of all the districts that most of the suburban areas have higher concentration of $\mathrm{NO}_{3}^{-}$in their tap water than city areas. However, the water sample from a residential quarter in Putuo District has much higher concentration of $\mathrm{NO}_{3}{ }^{-}$than the majority of other sampling sites in city areas. The water plant in charge for this quarter is Yangshupu Water Plant, and the water source is the Huangpu River. Other sampling sites belonging to the Yangshupu Water Plant are not found to have higher concentration of $\mathrm{NO}_{3}{ }^{-}$than the standard limit, so the high concentration of $\mathrm{NO}_{3}^{-}$from the residential quarter is likely to be caused by secondary pollution during the pipeline transportation.

The two sampling sites in Qingpu District are Qingpu Town and Xujing Town, each town having its own water plant. Xujing Water Plant has formally adopted the Submerged ultrafiltration membrane treatment process since July, 2011, the first to adopt this technology among all the water plants in Shanghai, and have supplied safer water ever since, with its $\mathrm{NO}_{3}{ }^{-}$concentration being 63\% lower than that of the water sample from Qingpu Town sampling site.

The average concentration of $\mathrm{PO}_{4}{ }^{3-}$ in tap water of the whole city of Shanghai is $1.14 \mathrm{mg} \cdot \mathrm{L}^{-1}$, which is much higher than the standard limit of drinking water quality of China. The main cause is possibly pollution near the water sources due to agricultural water with Phosphorus fertilizer, industrial water or domestic sewage etc.

The average concentration of $\mathrm{SO}_{4}{ }^{2-}$ in tap water of the whole city of Shanghai is $24.05 \mathrm{mg} \cdot \mathrm{L}^{-1}$, which is much lower than $100 \mathrm{mg} \cdot \mathrm{L}^{-1}$, the standard limit of drinking water quality of China. The highest concentration of $\mathrm{SO}_{4}{ }^{2-}$ is found from the Songyin water source where Jianshan 
District meets Songjiang district. This sampling site is at the point where the upper branches joins the Huangpu River, and the high concentration of $\mathrm{SO}_{4}{ }^{2-}$ in the water source might be the major cause. Whereas the sample taken from the Qingcaosha Reservoir within the city area has a lower concentration of $\mathrm{SO}_{4}{ }^{2-}$, because its water source is of better quality and enjoys a lower concentration of $\mathrm{SO}_{4}{ }^{2-}$ than the Huangpu River.

\section{B. Tap water quality evaluation}

Based on the classification method of Geographic Information System, and according the Nemerow index equation 1 to calculate the value of result, and considering $\mathrm{PO}_{4}{ }^{3-}$ have a large contribution to the Nemerow index, so we evaluate the tap water quality in two different conditions (taking no account of $\mathrm{PO}_{4}{ }^{3-}$ and considering $\mathrm{PO}_{4}{ }^{3-}$ ).

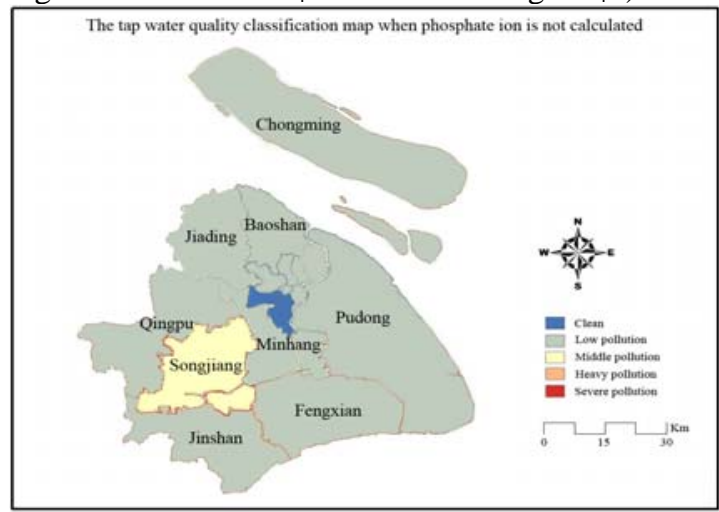

Figure 2. The tap water quality classification map when phosphate ion is not calculated

From Fig.2, taking no account of $\mathrm{PO}_{4}{ }^{3-}$, we can find that the tap water quality of most districts are low pollution and it becomes gradually clean from suburb to downtown. The most serious pollution district is Songjiang District, because there is a sample with high concentration of $\mathrm{NO}_{2}^{-}$, which make a great effort on the Nemerow index.

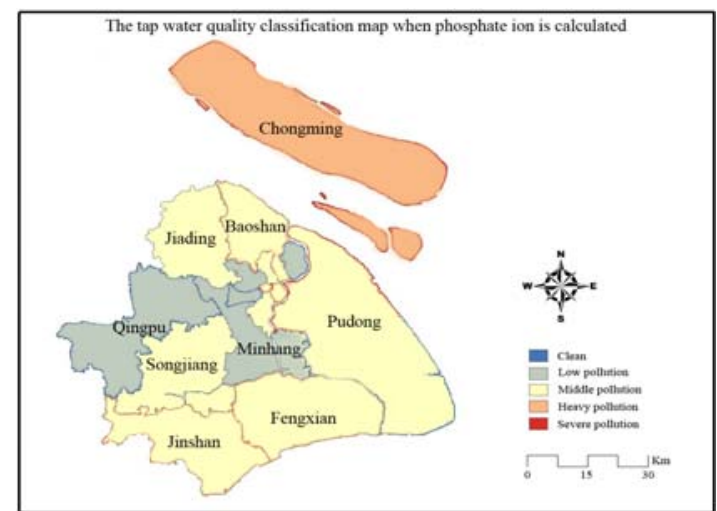

Figure 3. The tap water quality classification map when phosphate ion is calculated

From Fig.3, Considering $\mathrm{PO}_{4}{ }^{3-}$, we can find that the tap water quality of most districts are middle pollution and the coastal districts are more serious pollution than the inner districts. The most serious pollution district is Chongming county, because the concentration of $\mathrm{PO}_{4}{ }^{3-}$ is maximum in all of districts. The result of inorganic anions pollution with considering $\mathrm{PO}_{4}^{3-}$ is much more serious than taking no account of $\mathrm{PO}_{4}{ }^{3-}$. So $\mathrm{PO}_{4}{ }^{3-}$ have a large contribution to the Nemerow index.

\section{V.CONCLUSIONS}

The inorganic anions in Shanghai tap water from high to low by turns in terms of concentration are $\mathrm{Cl}^{-} 、 \mathrm{SO}_{4}{ }^{2-} 、 \mathrm{NO}_{3}{ }^{-}$、 $\mathrm{Br}^{-} 、 \mathrm{PO}_{4}{ }^{3-} 、 \mathrm{NO}_{2}{ }^{-}$. According to the Nemerow index, we find that tap water in most of the districts in Shanghai is polluted by inorganic anions. By comparing the experiments results of considering and not considering $\mathrm{PO}_{4}{ }^{3-i n}$ analyzing tap water in Shanghai, we find that $\mathrm{PO}_{4}{ }^{3-}$ has a large contribution to the Nemerow index and that phosphorus pollution is serious in Shanghai.

\section{ACKNOWLEDGEMENTS}

The research work was supported by research and innovation project of Shanghai Municipal Education Commission (12YZ082), leading academic discipline project of Shanghai Normal University (DZL809) and Shanghai Institute of Tourism research project (lyjyjx201405).

\section{REFERENCES}

[1] Rookj J. Formation of haloforms during chlorintion of natural waters. Water Treat Exa, 23, pp. 234, 1974.

[2] NCI U S. Report on the carcinogenesis bioassay of chloroform ( CAS No. 67-66-3) TR-000 NT IS Rpt No PB264018 bethesda, MD: National Cancer Institute, 1976.

[3] Will D K, Loraine D M. Case-control study of bladder cancer and chlorination by-products in treated water (Ontario, Canada). Cancer Causes \& Control, 7(6), pp. 596-604, 1996.

[4] Chen Zhuo, Yang Chengyong, Zou Huixian. Study Progress On Strong Mutagen in chlorinated tap water. Shanghai Environmental Sciences, 19(5), pp. 211-215, 2000.

[5] Wang Xiaolong, Ye Bixiong, Wang Xinyu, Han Zhiyu, Wei Jianrong, Yang Linsheng. Production rule of by-products in different disinfection processes of tap water. China Water \& Wastewater, 26(21), pp. 96-97, 2010.

[6] Liu Yongjian, Hou Xiaoping, Mou Shifen. Disinfection by-products in drinking water. Techniques and Equipment for Environmented Pollution Control, 2(2), pp. 31-40, 2001.

[7] The Songliao River Basin Water Environment Monitoring Center. Technical regulation of water quality sampling. Beijing: China Water Power Press, 2000.

[8] Lin Huaying, Sheng Lina, Li Yidan, Zhang Qiong, Lin Yao. Determination of twelve sorts of inorganic anion in drinking water by ion chromatography, Chinese Journal of Health Laboratory Technology, 19(10), pp. 2289-2290, 2009.

[9] Nemerow N L. Scientific stream pollution analysis, New York: McGraw-Hill, 1974.

[10] Lu Ning, Huang Xin, Gao Naiyun, Liu Hongbo, Zhang Dong. Bromonium Ion and Its Bromate Formation Potential in Raw Water of Qingcaosha Reservoir. Water Purification Technology, 30(3), pp. 10-12, 19, 2011. 